\title{
In situ quantitative three-dimensional characterisation of sub-indentation cracking in polycrystalline alumina
}

\author{
Yelena Vertyagina ${ }^{\mathrm{a}, 1}$, Mahmoud Mostafavi ${ }^{\mathrm{b}, 2}$, Christina Reinhard ${ }^{\mathrm{c}}$, Robert Atwood ${ }^{\mathrm{c}}$, James Marrow ${ }^{\mathrm{a}, \mathrm{d}}$ \\ ${ }^{a}$ Department of Materials, The University of Oxford \\ ${ }^{b}$ Department of Mechanical Engineering, The University of Sheffield, UK \\ ${ }^{c}$ Diamond Light Source, Harwell Science and Innovation Campus, Oxfordshire, UK \\ ${ }^{\mathrm{d} O x f o r d}$ Martin School, The University of Oxford, UK
}

\begin{abstract}
The three-dimensional deformation beneath a Vickers indentation in polycrystalline alumina has been measured, in situ, by digital volume correlation of high resolution synchrotron X-ray computed tomographs. The displacement fields at the peak indentation load and after unloading are used to study the shape and orientation of sub-surface cracks induced by the indentation; lateral cracking due to residual stresses, bounded by a system of radial cracks, is revealed. For the first time, it is shown that radial cracks have mixed mode opening displacements, which are affected by the relaxation of residual stresses via lateral cracking. This novel technique may find applications in the study of surface damage by abrasive wear in brittle materials.
\end{abstract}

Keywords: indentation; digital volume correlation; alumina; crack.

\section{Introduction}

Understanding indentation cracking in hard, brittle materials such as structural ceramics is important, since indentation damage contributes to certain forms of wear [1-3]. In the process of indentation a system of sub-surface cracks of various shapes and character is generated to accommodate the indentation strain. A significant residual plastic deformation zone can also form under an indentor; this may strongly modify the residual stress field in the surrounding elastic area once the load is removed, which can further develop cracking under the contact $[4,5]$. The removal of material from abraded surfaces can depend on the shape and orientation of indentation cracks, and also the indentation-induced residual stresses that act on them; hence, quantitative studies of these are necessary. Whilst it is routine to examine the surfaces of indented materials to characterise the extent and patterns of surface cracking, there are very few observations of indentation cracking below the surface [5-7]. Such studies are usually destructive, and may therefore modify the residual stress state during their observation [8]. Optical microscopy of transparent materials can detect significant cracks non-destructively, but cannot visualise clearly small defects directly below the indentation due to the deformation of the surface. Surface crack lengths are readily measured, but there are very few measurements of the crack opening displacements, which have a size of the order of a few micrometers [9]. A precise, non-destructive method is required to study and measure indentation cracks, in order to validate models of

\footnotetext{
${ }^{1}$ Corresponding author. Tel.: +44 7580225833. E-mail address: yelena.vertyagina@materials.ox.ac.uk

${ }^{2}$ This work was performed while M. Mostafavi was a James Martin Research Fellow in the Oxford Martin School at the University of Oxford.
} 
This is the author's copy of a paper subsequently published in the Journal of the European Ceramic Society (http://dx.doi.org/10.1016/j.jeurceramsoc.2014.04.002)

indentation damage and wear $[10,11]$. Such a method should also provide information on the residual stresses that remain after indentation.

One method for studying the internal structure of materials is computed X-ray tomography, which can be applied with sub-micron resolution to materials that are opaque to visible light; the obtained 3D datasets can be analysed by digital image correlation methods to measure the full field displacements that arise from damage and cracking $[12,13]$. This combined tomography/image correlation methodology has been applied here, for the first time, to investigate its suitability to study the cracks that develop in a model brittle material, polycrystalline alumina, during indentation by a pyramidal Vickers diamond.

\section{Material and Experiment}

Polycrystalline $\mathrm{Al}_{2} \mathrm{O}_{3}$ was selected as a model brittle material; its nominal properties were 99.5\% purity, density $3.8 \mathrm{~g} / \mathrm{cm}^{3}$, Young's modulus $350 \mathrm{GPa}$, flexural strength $375 \mathrm{MPa}$ and $1 \mathrm{~kg}$ Knoop hardness 13.7. Synchrotron X-ray computed tomography, of a cuboid $3 \mathrm{~mm} \times 3 \mathrm{~mm} \times 4 \mathrm{~mm}$ high, was performed at the Diamond Light Source, Joint Engineering, Environmental and Processing beamline (I12 - JEEP), with 4500 radiographic projections over a $180^{\circ}$ rotation at an X-ray beam energy of $53 \mathrm{keV}$; each projection had a field of view of $3.6 \mathrm{~mm} \times 2.4 \mathrm{~mm}$. The sample to detector distance was approximately $300 \mathrm{~mm}$, and the duration of each scan was 3 hours. The filtered backprojection reconstructed tomograms, with a nominal voxel size of $0.9 \mu \mathrm{m}$, contained image defects in the form of the concentric 'ring artefacts'; these are caused by instrumental factors and can adversely influence image correlation analysis of displacements; we used a combined Fourierwavelet algorithm [14] for their effective elimination. The sample dimension was larger than the field of view in some projections, however no local or region of interest tomography reconstruction methods were used. The indentation was applied to the as-received (i.e. as-sintered, un-cut) top surface of the sample under displacement control using a Vickers pyramidal diamond. The sample was imaged: (i) 'before' indentation (with a $10 \mathrm{~N}$ indentation load to fix the sample position); (ii) in situ at the maximum indentation load of $330 \mathrm{~N}$, and (iii) after removal of the load. The peak load of $330 \mathrm{~N}$ dropped to $300 \mathrm{~N}$ during the tomography scan.

\section{Results and Discussion}

The fine pore structure of the alumina is quite well resolved by tomography, as shown an xysection of the tomographic image at peak load, just below the indentation (Figure 1a). The surface of the sample is defined as the horizontal $x y$-plane with its origin in the upper left corner; the vertical $z$-direction is measured as the depth into the sample. Low contrast features emanating from the indentation are observed in this figure. Comparison with the optical image of the indented surface (Figure 1b) shows these features are a system of four approximately orthogonal radial cracks, which are slightly visible due to phase contrast; their attenuation contrast is negligible, which indicates the crack openings are sub-voxel size. Vertical sections through tomography image of the indented sample, close to an indentation diagonal (Figure 1c), reveal also a near-vertical low contrast feature that decreases in size as the load is removed. The phase contrast is insufficient to visualise the three-dimensional shape of the cracks, so a more detailed investigation was conducted using 3D digital image correlation, also known as digital volume correlation, to measure the displacement fields within the loaded and unloaded tomographs.

The digital volume correlation (DVC) analysis was performed using the LaVision Strain Master 8.1 software [15]. DVC correlates sub-volumes (termed an interrogation window or interrogation subset) of the deformed image with an initial reference image to map their relative displacements [16]. The accuracy of displacement measurement depends on the size of the interrogation subset; too small a size can lead to increased noise, whereas large subsets coarsen the spatial resolution of the displacement field data. Each dataset for the DVC analysis measured $2600 \times$ $2600 \times 2000$ voxels (13 GB at 8-bit), cropped from the original tomographs of $4016 \times 4008 \times 2672$ 
This is the author's copy of a paper subsequently published in the Journal of the European Ceramic Society (http://dx.doi.org/10.1016/j.jeurceramsoc.2014.04.002)

voxels (160 GB as 32 bit data). Coarse rigid body translations between datasets were corrected before DVC analysis by visual matching and registration of image slices in an $x y$ plane close to the indented surface. The image correlation parameters found to be optimal for these data were a 256 $\times 256 \times 256$ voxel interrogation subset, with $50 \%$ overlap and 2 passes, followed by a $128 \times 128 \times$ 128 interrogation subset, with $75 \%$ overlap and 3 passes. Smaller interrogation subsets substantially increased the noise in the displacement field, by a factor of almost 2 . The overlap is the fraction of the previous interrogation subset that is included in an adjacent subset during the analysis. The displacements are obtained iteratively as the number of passes of the interrogation subset through the data is increased. The output data were the 3D full field displacements, strains (i.e. displacement field gradients) and also the correlation coefficient for each interrogation window; these values are reported at the centre of the interrogation window, hence the data closest to the surface are at a representative depth of $z=57.6 \mu \mathrm{m}$ (i.e. 64 voxels). The first tomography scan (at 10 $\mathrm{N}$ ) was used as the reference for the DVC analysis of both the peak-loaded and un-loaded scans.

There is an inevitable rigid body rotation of the sample between successive scans due to the effects of mechanical loading in a system that is not infinitely stiff. This was removed by geometrical transformation of the DVC-obtained displacement field, setting the relative displacement between samples to zero at their base; a position that was remote from the indentation and its deformation field. The displacement vector reference system then becomes better aligned with the axes of the sample and the indentation loading by fine correction of the rigid body movements. This is particularly important when the measured displacements are small [17]. To do this, the rigid body rotation was decomposed into a sequence of six shear transformations; one can determine two shear angles for each planar slice or layer along axes lying in this plane. A similar transformation is applied to all layers in the orthogonal planes, resulting in a body rotation; the use of all six conforming shears rotates the body around all three axes [18-20]. The transformations are applied to the displacement field dataset, and because it is considerably smaller than the tomography dataset (by a factor of up to $1 / 128^{3}$ in this case), this method is computationally more efficient than correction by rotation of one of the tomography images. There is also no requirement for interpolation of the image data.

The displacement measurement uncertainty, estimated as the standard error after rotation correction from a region of negligible deformation that was remote from the indentation, was 0.28 $\mu \mathrm{m}$ for the loaded state and $0.45 \mu \mathrm{m}$ for the final unloaded state (i.e. $\sim 0.3$ and 0.5 voxel respectively). The deformation under the indentation can be visualised as a strain field, calculated from the displacement field gradients. For example, the magnitude of the maximum principle strain is shown in Figure 2a, in which high strains directly under the indenter are noticeable. However, these strain data are insufficient for quantitative evaluation of the cracking that arises from indentation; this is due to the uncertainty in the displacement data, which accentuates noise in the strain field. Image correlation can measure crack opening displacements that are significantly smaller than one voxel; both 2D and 3D digital image correlation analyses have been used previously to study the opening displacements of non-visible cracks [21] by measurement of the relative displacements of material on either side. Data for the total displacement vector magnitudes are shown for an $x-y$ plane close to the indented surface in Figure $2 b$ (data at peak load); these reveal a complex and non-symmetric pattern of displacements, caused by cracking.

Lateral cracks are planar features that form below the indentation and lie approximately parallel to the indented surface $[7,22]$. They are not discernable in the tomographs, but their presence can be detected by analysis of the displacement data. The z-displacements in an $x y$-plane close to the top surface at the peak load are shown in Figure 3a; the maximum displacement is below the indentation, as expected. The displacements of the same plane after unloading, relative to the original unloaded state, are shown in Figure $3 \mathrm{~b}$; negative values reveal an uplift that extends over a region that is comparable to the radial cracks' surface length; there is a much less significant uplift in the quadrant between radial cracks 1 and 2 . This pattern is consistent with the lateral crack 
This is the author's copy of a paper subsequently published in the Journal of the European Ceramic Society (http://dx.doi.org/10.1016/j.jeurceramsoc.2014.04.002)

growth being limited by the pre-existing radial cracks and indicates their the net opening is of the order of $1 \mu \mathrm{m}$. A line profile parallel to the $z$-axis shows vertical displacements are not measurable beyond $300 \mu \mathrm{m}$ from the surface (Figure 3c), indicating that the lateral cracks occur well within this distance. Horizontal displacements for the same line profile (Figure 3d) show a shear displacement in the $y$-direction; there is no significant shear in the $x$-direction. The lateral cracks experience mixed-mode loading.

The radial crack openings were measured by assessing the relative displacements on either side of the cracks, which were approximately perpendicular to the surface. Ideally these would be measured using the displacement vectors adjacent to the opposing faces of the cracks, but image correlation measurement is prone to error when the interrogation subsets overlap a discontinuity [23]. The actual relative displacement across a crack, between points on either side in its vicinity, is approximately constant with increasing distance between the points [21], so the crack opening displacement vectors can be mapped by a point-to-point comparison between parallel vertical planes that are sufficiently remote from the discontinuity to be insensitive to its effect on the image correlation analysis. Examination of the displacement fields, and the effect of distance, found a measurement distance of 750 voxels $(\sim 0.67 \mathrm{~mm})$ to be sufficient. The relative displacements parallel and perpendicular to the crack plane were calculated for the four radial cracks; a $2 \times 2 \times 2$ moving average was used to reduce the effects of noise. This process was judged to give an approximate and consistent measure of the material displacements from the crack opening, though the measured displacements may be an under-measurement of the true displacements [21].

The data obtained from the displacement fields at peak load and also after unloading are summarised in Figure 4. They show both opening (mode I) and shear displacements across the cracks. At the peak load, close to the surface, whilst only cracks 1 and 2 have significant mode I opening displacements (of the order of $1 \mu \mathrm{m}$ ) (Figure 4a), cracks 1, 2 and 4 exhibit horizontal shear displacements of similar magnitude (Figure 4b). Cracks 1, 2 and 3 show vertical shear displacements close to the surface only after unloading (Figure 4c). Unloading reduces the horizontal shear displacements below the surface, but does not significantly affect the near surface displacements (Figure 4b). Interestingly, the maximum opening displacements of cracks 1, 2 and 3 increase on unloading (Figure 4a), as do the horizontal shear displacements of these cracks close to the surface; this is consistent with Lawn's observation that a radial crack is expected to continue its growth until unloading is complete [4]. The vertical shear displacements also are only significant for cracks 1 and 2 after unloading (Figure 4c). It is not possible to identify the crack tip positions reliably from these data, but the measurements indicate radial crack depths of several hundred $\mu \mathrm{m}$; these are of similar magnitude to the optically observed surface lengths. The crack opening displacements after unloading are only significant close to surface, which implies they are affected by the development of lateral cracking. A schematic approximation of the directions of the relative vertical and horizontal shear displacements of the radial cracks, at both peak load and after unloading, is shown in Figure 4d, which illustrates the complexity of the deformation.

One of the goals of three-dimensional measurement of cracks and their displacement fields is to obtain a sufficient description of mechanical driving force acting on them. There are various methods for this in 2D and 3D (e.g. [13, 24, 25]). The present data are, however, are insufficient due to the small size of the cracks and their complex shape. Similar experiments on larger cracks, or with higher resolution tomography, will accomplish this.

\section{Conclusions}

A novel non-destructive technique for the study of indentation cracking has been demonstrated, using in situ high resolution X-ray tomography with subsequent digital volume correlation to obtain the full 3D displacement field. This allows quantitative characterisation of the opening and shear displacements of sub-surface indentation cracks. For the first time, the shear components of indentation cracks have been measured; these have magnitudes comparable to the 
This is the author's copy of a paper subsequently published in the Journal of the European Ceramic Society (http://dx.doi.org/10.1016/j.jeurceramsoc.2014.04.002)

opening displacements, which are approximately $1 \mu \mathrm{m}$. Lateral cracks, also with opening displacements of approximately $1 \mu \mathrm{m}$, develop with unloading and are bounded by the radial cracks that formed on loading. It is proposed that this technique of crack characterisation is well suited to the study of indentation and role of residual stresses on damage development during abrasive wear in brittle materials.

\section{Acknowledgements}

This work was carried out with the support of the Diamond Light Source; the authors acknowledge the beam time award at the Joint Engineering, Environmental and Processing (I12) beamline (Experiment EE7730) and the help of Dr D.M. Collins, Dr H. Çetinel and Mr S. Barhli to conduct the experiment. MM and TJM gratefully acknowledge the support of Oxford Martin School, MM acknowledges the support of Linacre College, Oxford through a Junior Research Fellowship and YV acknowledges the support of EDF Energy UK. The Manchester X-Ray Imaging Facility (Dr S.A. McDonald and Professor P.M. Mummery) are thanked for the loan of the loading rig. Professor R.I. Todd, The University of Oxford, is thanked for valuable discussions. Almath Crucibles are thanked for supplying the alumina.

\section{Figures}

Figure 1: The indentation: a) $x-y$ section of the tomographic image at the indented surface (slice at $z=0$ ), observed in situ in the peak loaded scan; b) optical image of the indented surface after indentation; $c$ ) vertical cross-sections of the loaded (i) and unloaded (ii) sample. The trace of the section is shown in Figure $2 \mathrm{~b}$.

Figure 2: DVC analysis of the deformation: a) Cross-section of the indenter and indented microstructure and maximum principal strain map in the peak loaded state; b) total displacement near the surface of the loaded sample ( $z=57.6 \mu \mathrm{m}$ or 64 voxels) with crack traces and the trace of the sections of Figure $1 \mathrm{c}$ indicated.

Figure 3: Displacements in $z$-direction, in the $x-y$ plane at $z=57.6 \mu \mathrm{m}$ (64 voxels) near to the top surface of the loaded (a) and unloaded (b) samples (the indentation position is marked by ' + '; the displacement scale is the same for both plots); c) line profile of the vertical displacement along a trace through the indentation, approximately parallel to radial cracks 1 and 3 ; d) depth profile of the displacements under the point marked ' $x$ ' for the finally unloaded sample (see Figure $3 b$ ).

Figure 4: The relative opening displacements of the radial cracks for the (i) loaded and (ii) unloaded states; a) mode I opening, perpendicular to the crack plane; b) horizontal shear, parallel to the crack plane; c) vertical shear, parallel to the crack plane; d) schematic illustration of the shear displacements (the magnitudes are not representative of the measured displacements).

\section{References}

[1] Lawn BR. Indentation of ceramics with spheres: A century after Hertz. J Am Ceram Soc 1998; 81:1977-94.

[2] Chauhan R, Ahn Y, Chandrasekar S, Farris TN. Role of indentation fracture in free abrasive machining of ceramics. Wear 1993; 162-164:246-57.

[3] Miyazaki H, Hyuga H, Yoshizawa Y-i, Hirao K, Ohji T. Correlation of wear behavior and indentation fracture resistance in silicon nitride ceramics hot-pressed with alumina and yttria. J Eur Ceram Soc 2009; 29:1535-42.

[4] Lawn BR, Evans AG, Marshall DB. Elastic/Plastic Indentation Damage in Ceramics: The Median/Radial Crack System. J Am Ceram Soc 1980; 63:584-1.

[5] Cook RF, Pharr GM. Direct Observation and Analysis of Indentation Cracking in Glasses and Ceramics. J Am Ceram Soc 1990; 73:787-817.

[6] Lube T. Indentation crack profiles in silicon nitride. J Eur Ceram Soc 2001; 21:211-8.

[7] Elfallagh FA, Inkson BJ. 3D tomographic analysis of crack morphologies in alumina and glass using FIB microscopy. J Phys Conf Ser 2008; 126:012080. 
This is the author's copy of a paper subsequently published in the Journal of the European Ceramic Society (http://dx.doi.org/10.1016/j.jeurceramsoc.2014.04.002)

[8] Guo S, Todd RI. Quantitative optical fluorescence microprobe measurements of stresses around indentations in $\mathrm{Al} 2 \mathrm{O} 3$ and $\mathrm{Al} 2 \mathrm{O} 3 / \mathrm{SiC}$ nanocomposites: The influence of depth resolution and specimen translucency. Acta Mater 2011; 59:2637-47.

[9] Kruzic JJ, Ritchie RO. Determining the Toughness of Ceramics from Vickers Indentations Using the Crack-Opening Displacements: An Experimental Study. J Am Ceram Soc 2003; 86:1433-6.

[10] Qasim T, Ford C, Bush MB, Hu X, Lawn BR. Effect of off-axis concentrated loading on failure of curved brittle layer structures. J Bliomed Mater Res B 2006; 76:334-9.

[11] Holmberg K, Laukkanen A, Ronkainen H, Wallin K, Varjus S. A model for stresses, crack generation and fracture toughness calculation in scratched TiN-coated steel surfaces. Wear 2003; 254:278-91.

[12] Mostafavi M, Baimpas N, Tarleton E, Atwood RC, McDonald SA, Korsunsky AM, et al. Threedimensional crack observation, quantification and simulation in a quasi-brittle material. Acta Mater 2013; 61:6276-89.

[13] Limodin N, Réthoré J, Buffière J-Y, Gravouil A, Hild F, Roux S. Crack closure and stress intensity factor measurements in nodular graphite cast iron using three-dimensional correlation of laboratory X-ray microtomography images. Acta Mater 2009; 57:4090-101.

[14] Münch B, Trtik P, Marone F, Stampanoni M. Stripe and ring artifact removal with combined wavelet-Fourier filtering. Opt Express 2009; 17:8567-91.

[15] DaVis. User's Manual. Gottingen: LaVision GmbH; 2012.

[16] Bay BK, Smith TS, Fyhrie DP, Saad M. Digital volume correlation: Three-dimensional strain mapping using x-ray tomography. Exp Mech 1999; 39:217-26.

[17] Mostafavi M, Vertyagina Y, Reinhard C, Bradley R, Jiang X, Galano M, et al. 3D studies of indentation by combined X-ray tomography and digital volume correlation. Key Eng Mat 2014; 592-593:14-21.

[18] Paeth AW. A fast algorithm for general raster rotation. Proc Graph Interf 1986; 77-81.

[19] Toffoli T, Quick J. Three-Dimensional Rotations by Three Shears. Graph Model Im Proc 1997; 59:89-95.

[20] Chen B, Kaufman A. 3D Volume Rotation Using Shear Transformations. Graph Models 2000; 62:308-22.

[21] Mostafavi M, McDonald SA, Çetinel H, Mummery PM, Marrow TJ. Flexural strength and defect behaviour of polygranular graphite under different states of stress. Carbon 2013; 59:325-36.

[22] Marshall DB, Lawn BR, Evans AG. Elastic/Plastic Insentation Damage in Ceramics: The Lateral Crack System. J Am Ceram Soc 1982; 65:561-6.

[23] Bernard G, Hild F, S. R. Finite-Element: displacement field analysis from digital images: application to Portevin-Le Chatelier Bands. Exp Mech 2006; 46:789-803.

[24] Becker TH, Mostafavi M, Tait RB, Marrow TJ. An approach to calculate the J-integral by digital image correlation displacement field measurement. Fatigue Fract Eng M 2012; 35:971 -84 .

[25] Rethore J, Roux S, Hild F. An extended and integrated digital image correlation technique applied to the analysis of fractured samples. Eur J Comput Mech 2009; 18:285-306. 
a)

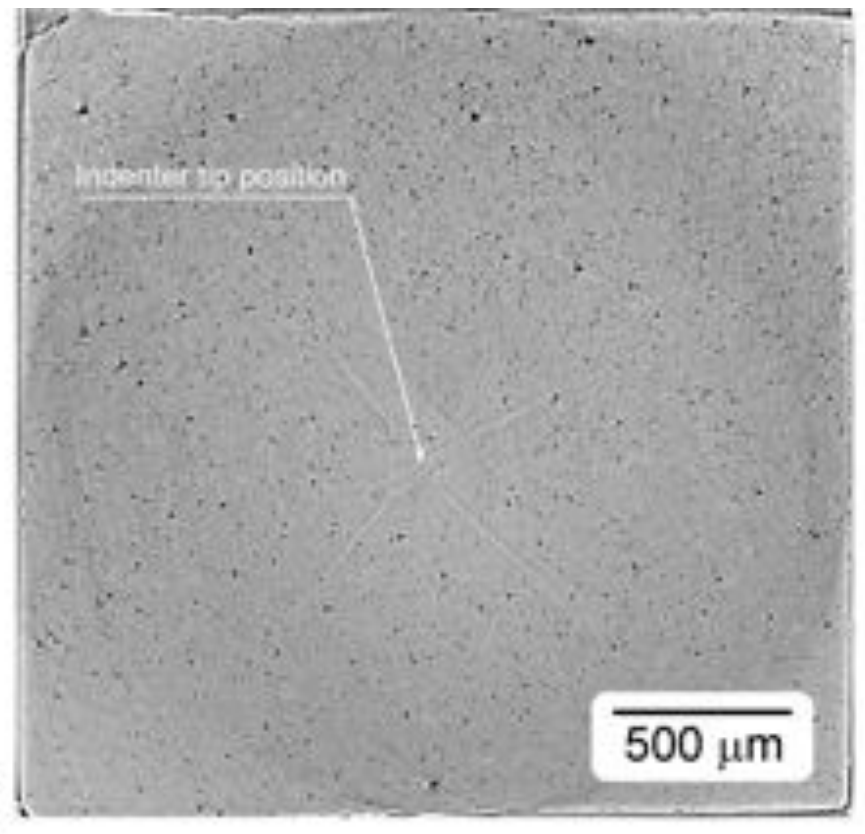

c) b)
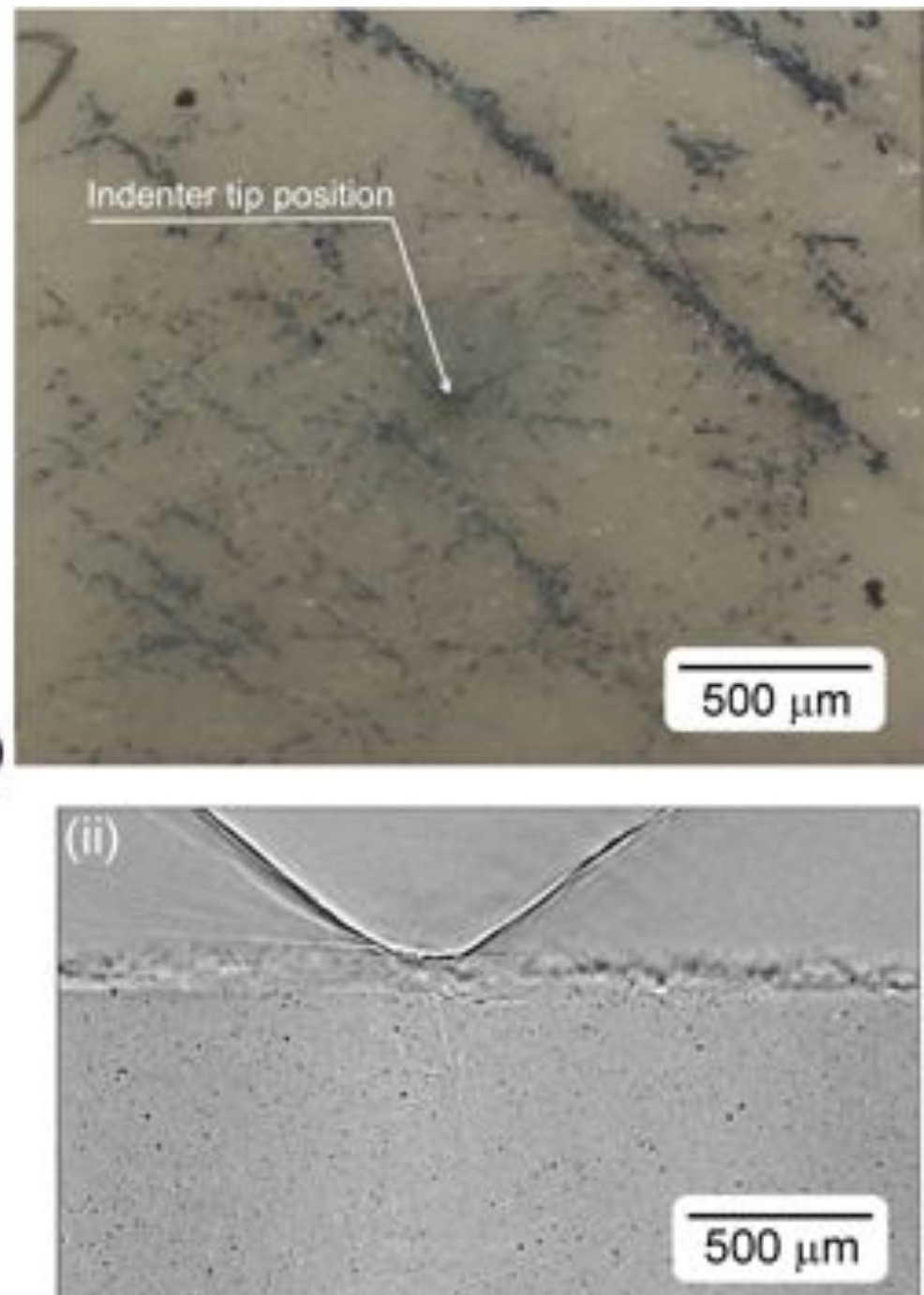

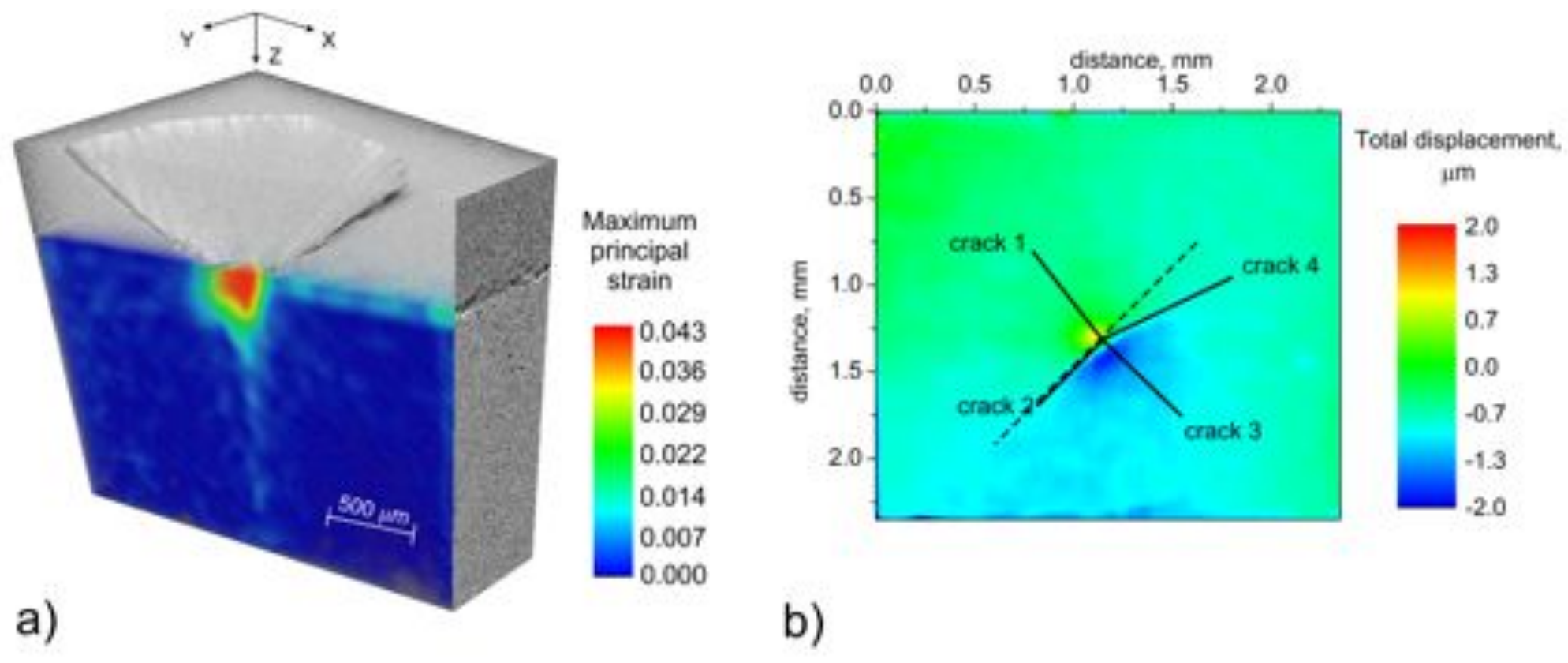


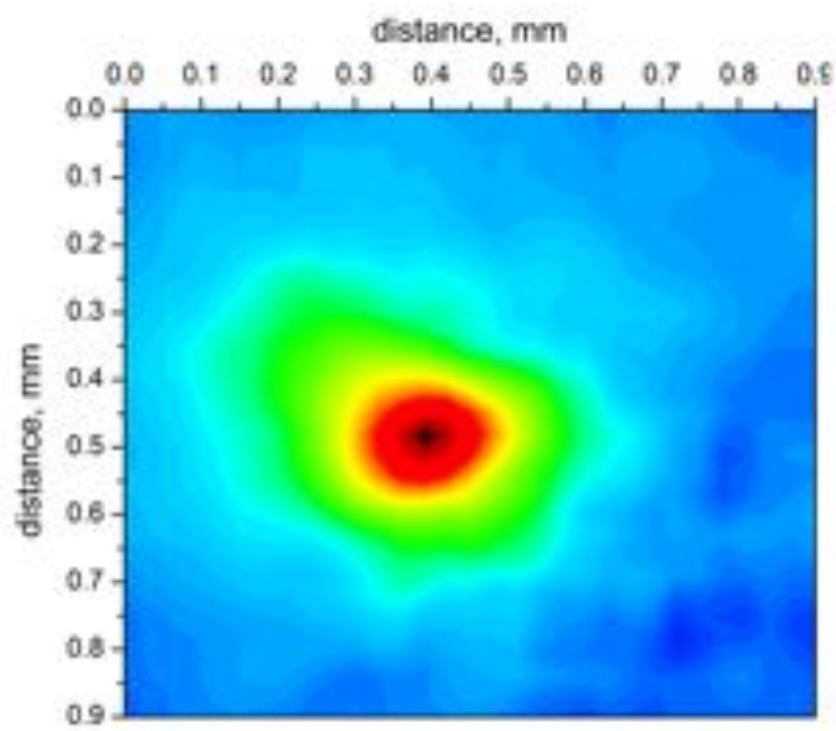

a)

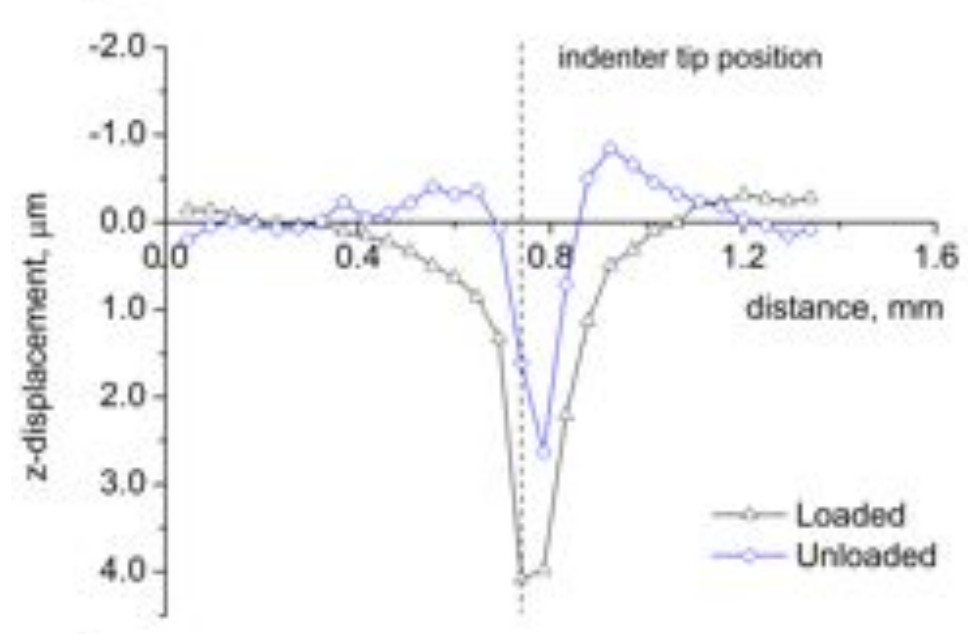

c)

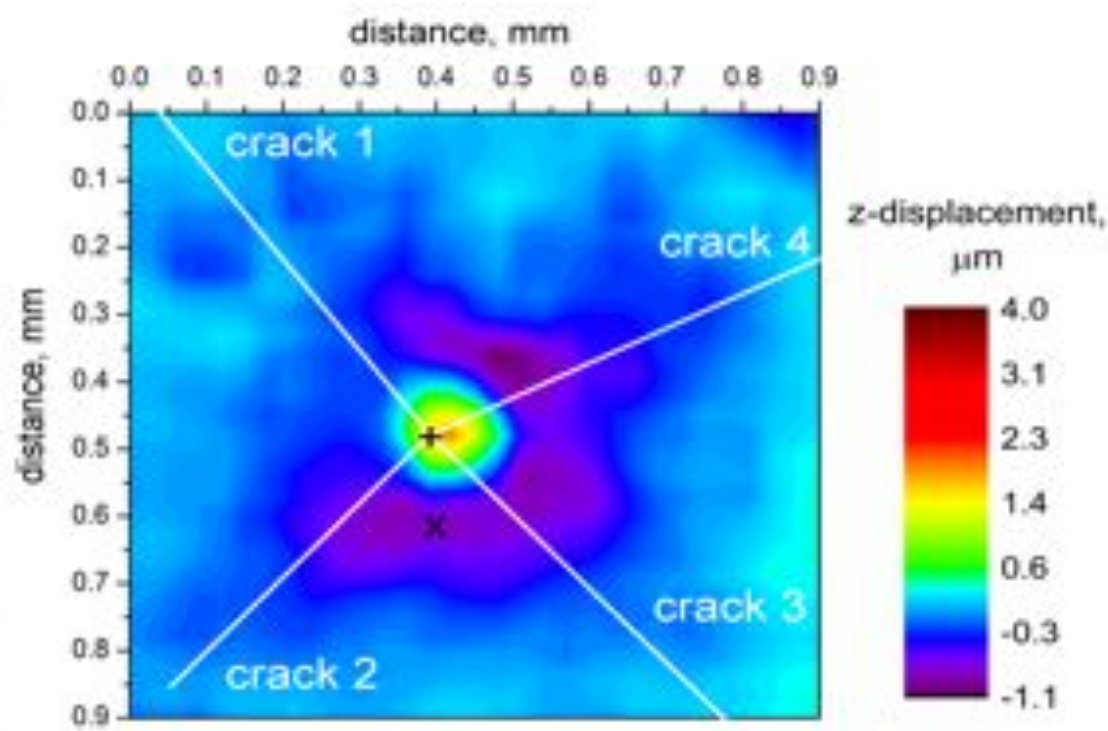

b)

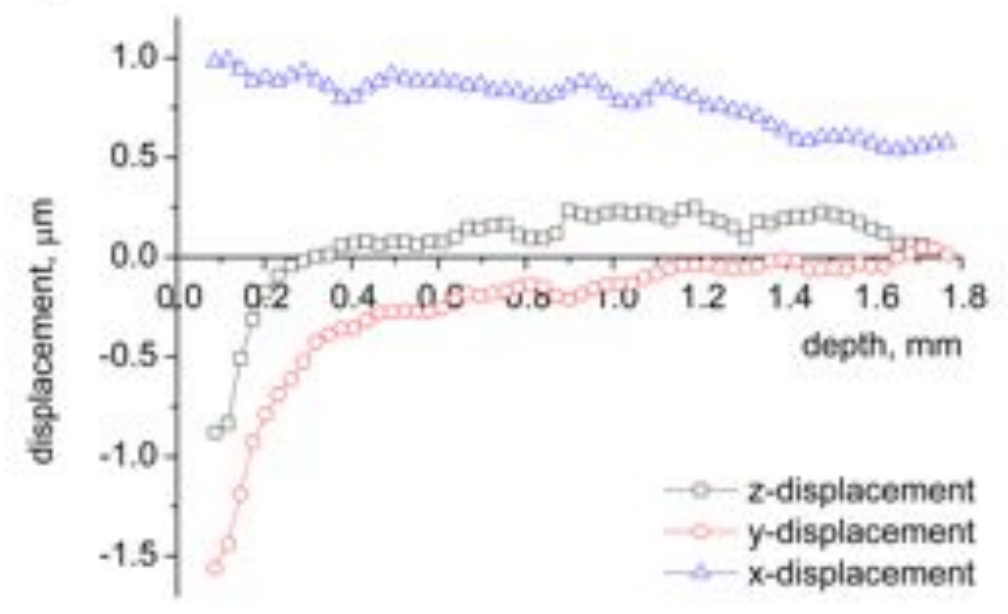

d) 

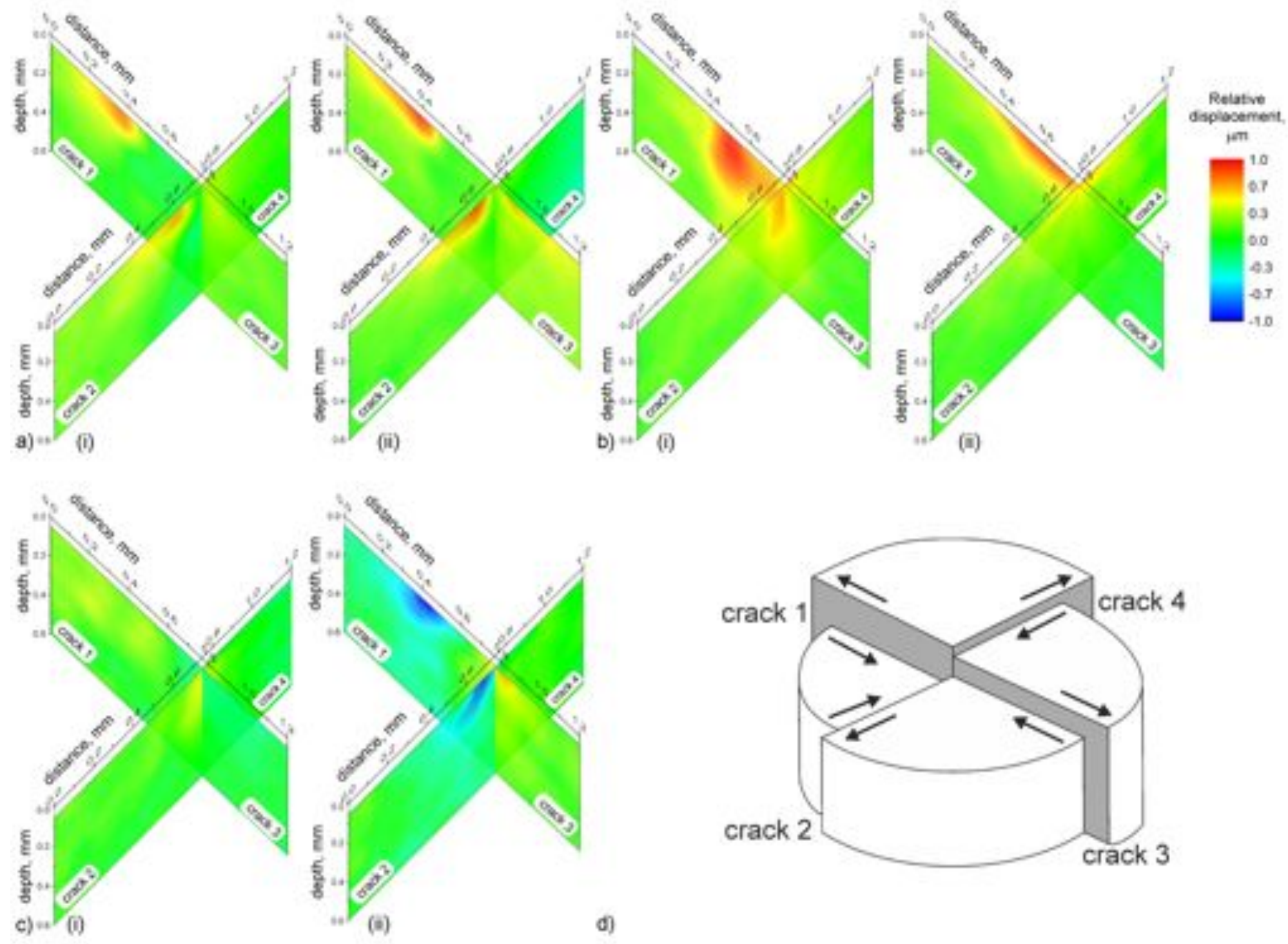